\title{
Correlation Between P-wave Velocity and Strength Index for Shale to Predict Uniaxial Compressive Strength Value
}

\author{
H. Awang ${ }^{1}$, N. R. Ahmad Rashidi ${ }^{1}, M$. Yusof ${ }^{1, *}$, and K. Mohammad ${ }^{2}$ \\ ${ }^{1}$ Institute for Infrastructure Engineering \& Sustainable Management, Universiti Teknologi MARA, \\ 40450 Shah Alam, Selangor, Malaysia \\ ${ }^{2}$ Faculty of Civil Engineering, Universiti Teknologi MARA, 40450 Shah Alam, Selangor, Malaysia
}

\begin{abstract}
Seismic refraction survey is a non destructive method used in site investigation to identify the seismic velocity subsurface strata. Although it is widely known, the reliability of the result is still doubtable for some reason as well as due to an engineer's ignorant, which insist on using conventional method rather than new advanced method causing the lack of usage in geophysical method for testing. This study aims to produce a correlation between $\mathrm{P}$-wave velocity value and point load strength index value for shale. Both field and laboratory tests were carried out. In order to obtain the P-wave value, seismic refraction method was conducted as a field test at Precint 4, Putrajaya, Malaysia to achieve the Pwave velocity value of the shale bed. Ten samples of shale were collected from the field and laboratory tests were conducted. The tests are divided into three sections, namely non-destructive laboratory test, physical properties test and mechanical properties test. Ultrasonic Velocity Test via PUNDIT test was conducted as non-destructive laboratory test to acknowledge the P-wave velocity value in laboratory. Both field and laboratory P-wave velocity value were then compared and the result delivers are reliable due to it is within the range. For physical properties test, the rock density and porosity were acknowledged. Meanwhile, Point Load Test was conducted as mechanical properties. Correlation for both Pwave velocity value and point load strength value were achieved via producing an empirical relationship as the end result. Prediction of uniaxial compressive strength (UCS) value was made via converting the point load strength value to UCS value using a correlation. By acknowledging this empirical relationship, it shows that geophysical methods are able to produce a reliable result. Hence more and widely used of geophysical method will be profound in the future.
\end{abstract}

\section{Introduction}

Prior to site investigation purposed, most of the methods used are destructive, consumed more time and high cost. Besides that, the results are discrete which is only single point of

\footnotetext{
* Corresponding author: haryatiawang@yahoo.co.uk
} 
data could be obtained. Underground profile produced from this method is from combining a few numbers of results of the holes points. A continuous profile shows the soil and rock layer by assuming the layer is similar from one point to another. However, the reliability of the result is still doubtable due to misinterpret of the profile between the points. Due to this, geophysical methods are now becoming popular in producing the subsurface profile especially in differentiating the soil and rock layers. Many studies have been conducted to prove the reliability of the geophysical test results as well as correlations between the geophysics and strength parameters to promote this advanced non-destructive method without the needs to use the conventional methods.

This study is about conducting a geophysical method called as seismic refraction as a non-destructive test method to obtain the subsurface profile of a site. Besides that, a laboratory test using pulse ultrasonic no-destructives test (PUNDIT) and other strength tests on samples collected from site were also conducted. The objectives of this study is to compare between the velocity of wave called as primary wave velocity ( $\mathrm{P}$-wave velocity, $\mathrm{v}_{\mathrm{p}}$ ) measured from field and laboratory. The other objective is to correlate between the Pwave velocity and point load strength for the purpose of estimating the uniaxial compressive strength (UCS) of the rock samples. The study was conducted at Precint 4, Putrajaya, Malaysia Fig. 1. This site lies on Kenny Hill's Formations that contain of shale, phylite, slate and sandstones.

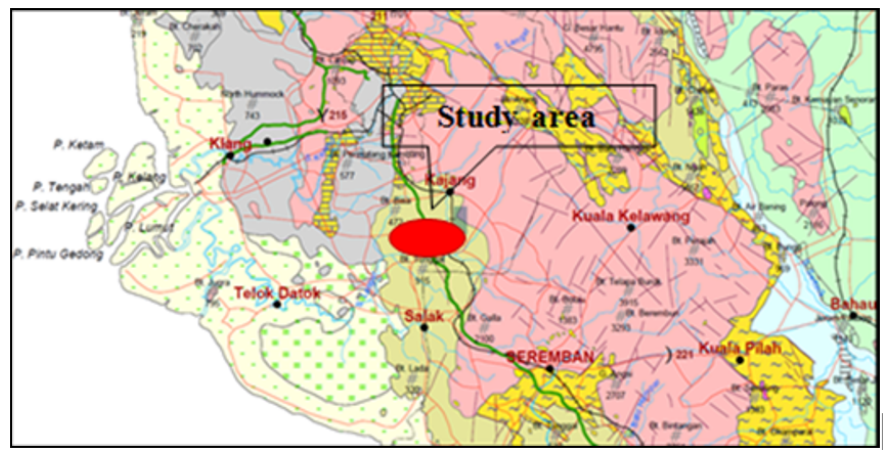

Fig. 1. Location of study area

\section{Theories and previous study}

This study applied seismic refraction method test that measures travel times of seismic waves throught ground layers via receivers at known-points along the ground surface. Basically seismic refraction technique is a measurement of time taken for the wave to travel from one location to another. As end result it produces P-wave velocity, and this value is then recorded for analysis. In recent years, the use of coconut fibre as reinforcement on concrete has received high attention because of renewability, low density, high specific properties and low cost.

In engineering applications, the used of P-wave velocity value is proven to be important due to the parameters of Poisson's ratio and Young's modulus. The relationship between velocity $\left(\mathrm{v}_{\mathrm{p}}\right)$ and Young's modulus $(E)$ is address as,

$$
v_{p}=\sqrt{\frac{E}{\rho}}
$$


where $\rho$ is density of material; $E$ and $\mathrm{v}_{\mathrm{p}}$ have been define as above. The use of these parameters could be used to calculate foundation settlement on rock according to [1] as in Equation (2).

$$
S=\frac{\pi}{2}\left[\frac{q\left(1-v^{2}\right) R}{E}\right](\operatorname{Ig})
$$

where $S, q, E, I g, R$ and $v$ is for settlement, uniform load per area, Young's modulus, depth reduction factor, radius of the pile and Poisson's ratio accordingly. This equation shows the relation between Poisson's ratio, Young's modulus and P-wave velocity. By substituting Equation (1) into (2) the settlement of foundation is calculated as:

$$
S=\frac{\pi}{2}\left[\frac{q\left(1-v^{2}\right) R}{\boldsymbol{\rho} v p^{2}}\right](I g)
$$

The physical and mechanical properties of rock are essential to predict the behavior of the rock mass. It can be achieved via conducting laboratory test on specimens collected from the field. [2] found that among the rock mass properties involved are the rock type, strength, and degree of alteration, structure, fabric abrasiveness, moisture content and the seismic velocity.

Uniaxial compressive strength (UCS) value is an important engineering parameter needed in construction design due to the rock strength. The prediction model is developed by converting the value from the result achieved by PLT to UCS value using a correlation factor. [3] stated that the correlation factor to convert the result achieve from PLT to UCS as in Equation (4).

$$
U C S=14.10 I_{550}+4.50
$$

[4] produced a prediction model between uniaxial compressive strength (UCS) and Young's modulus $(E)$ acknowledged as :

$$
E=0.3752 U C S+4.428
$$

\section{Experimental studies}

\subsection{Field test}

Test begins with conducting a seismic field test at Precint 4, Putrajaya. A total of 24 geophones were pinned into the ground along the site with a total length of $115 \mathrm{~m}$ with interval $5 \mathrm{~m}$ between the geophones. The seismic energy source was triggered by $8 \mathrm{~kg}$ hammer shot on steel plate at the ground surface. As the wave travel in refracted path the travel times is recorded by the geophones as receivers. The velocity of the wave is determined by calculating the time taken for each distance of the receiver points. Offset were set up at $0.5 \mathrm{~m}$ for both end sides. Seismometer was placed in the middle of the layout between geophones 12 and 13. The line was named as SL1. Fig. 2 shows the field setup for the seismic refraction method. 


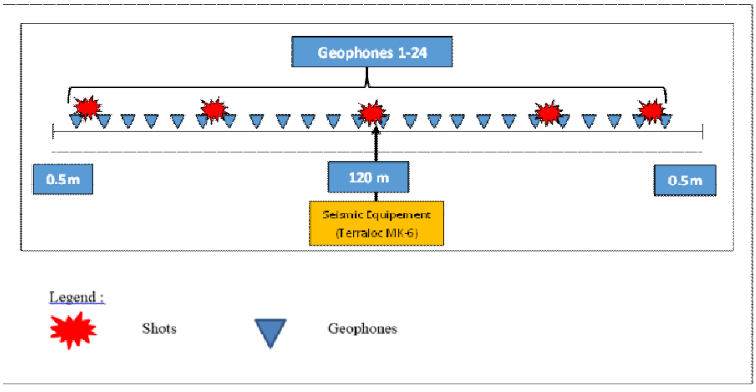

Fig. 2. Field setup for the seismic refraction method (SL1)

\subsection{Laboratory tests}

For laboratory experimental study, ten irregular specimens were collected for PUNDIT and point load test (PLT). Density and porosity tests on the other hand were conducted to acknowledge the physical properties of the rock. Samples were collected from the location of field testing as the used to conduct laboratory testing in broken cored form. It represent characteristics and properties of rock material of the field. Samples received were in irregular condition due to weak condition of the rock which is soft and easily to break into parts. Therefore, to conduct the test, the best sample need to be chosen. The sample was chosen based on their conditions which is no fractured occurring at the specimens. Apart from that the sample dimension also were considered to ensure that the specimen size are eligible for laboratory tests.

\section{Results and discussion}

The results of field test is presented as a seismic tomogram profile as in Fig. 3. The profile was interpreted based on seismic velocity index by [5] demonstrates geological sections along the seismic refraction survey line consist of varieties of velocity. The upper layer (L1) consists of overburden soil with the P-wave velocity value ranging between $100 \mathrm{~ms}^{-1}$ and $1000 \mathrm{~ms}^{-1}$ which the thickness is approximately $9 \mathrm{~m}$. Layer 2 (L2) produced seismic velocity value of $2000 \mathrm{~ms}^{-1}$ to $3800 \mathrm{~ms}^{-1}$ with $21 \mathrm{~m}$ in thickness. The bottom layer (L3) has velocity more than $4000 \mathrm{~ms}^{-1}$ with the thickness value is considered to be approximately $2 \mathrm{~m}$. The seismic velocity of each layer is determined in range as summaried in Table 1 .

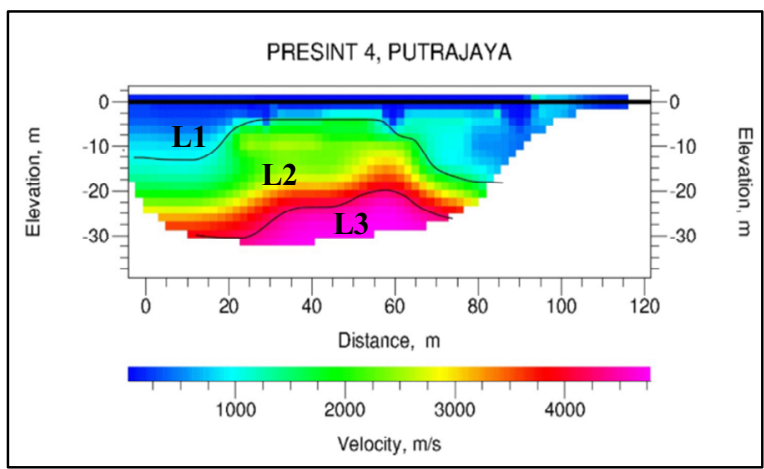

Fig. 3. P-wave velocity model produced 
Table 1. Typical primary (vp) velocities for different material

\begin{tabular}{ccc}
\hline Layer & $v_{p}\left(\mathrm{~ms}^{-1}\right)$ & Description \\
\hline 1 & $100-1000$ & Overburden soil \\
2 & $2000-3800$ & Shale \\
3 & $>4000$ & Sandstone \\
\hline
\end{tabular}

Result achieved via conducting the laboratory tests for porosity, density and Pulse wave value is tabulated in Table 2 .

Table 2. Results of density, porosity, P-velocity value, PLT and predicted UCS \& Young's modulus

\begin{tabular}{cccccccccc}
\hline $\begin{array}{c}\text { Sample } \\
\text { No }\end{array}$ & $\begin{array}{c}\text { Density } \\
\left(\mathrm{kg} / \mathrm{m}^{3}\right)\end{array}$ & $\begin{array}{c}\text { Porosity } \\
(\%)\end{array}$ & $\begin{array}{c}\text { Distance } \\
(\mathrm{mm})\end{array}$ & $\begin{array}{c}\text { Time } \\
(\mathrm{ms})\end{array}$ & $\begin{array}{c}\text { Velocity } \\
\left(\mathrm{ms}^{-1}\right)\end{array}$ & $\begin{array}{c}\text { Load } \\
(\mathrm{P}) \\
(\mathrm{kN})\end{array}$ & $\begin{array}{c}\text { Is }(50) \\
\text { Predicted } \\
\text { UCS } \\
(\mathrm{MPa})\end{array}$ & $\begin{array}{c}\text { E } \\
(\mathrm{GPa})\end{array}$ \\
\hline 1 & 2620 & 0.47 & 70 & 27.5 & 2545 & 4.70 & 1.87 & 30.87 & 16.01 \\
2 & 2341 & 0.52 & 69 & 22.7 & 3040 & 6.10 & 2.26 & 36.37 & 18.07 \\
3 & 2523 & 0.54 & 73 & 27.0 & 2704 & 5.50 & 2.17 & 35.10 & 17.60 \\
4 & 2418 & 0.48 & 63 & 21.5 & 2930 & 5.80 & 2.31 & 37.07 & 18.34 \\
5 & 2489 & 0.59 & 63 & 21.0 & 3000 & 5.70 & 2.25 & 36.23 & 18.02 \\
6 & 2335 & 0.51 & 71 & 24.5 & 2898 & 5.20 & 2.03 & 33.12 & 16.85 \\
7 & 2532 & 0.56 & 70 & 26.0 & 2692 & 5.00 & 1.99 & 32.56 & 16.64 \\
8 & 2612 & 0.49 & 69 & 22.5 & 3067 & 5.50 & 2.19 & 35.38 & 17.70 \\
9 & 2308 & 0.52 & 67 & 23.5 & 2851 & 5.90 & 2.28 & 36.65 & 18.18 \\
10 & 2471 & 0.51 & 68 & 25.0 & 2720 & 4.90 & 1.93 & 30.87 & 16.01 \\
\hline
\end{tabular}

For physical properties, as shown in Table 2 the density value ranging from $2308 \mathrm{~kg} / \mathrm{m}^{3}$ to $2620 \mathrm{~kg} / \mathrm{m}^{3}$. When compared to [6] the density value of shale ranging from $2300 \mathrm{~kg} / \mathrm{m}^{3}$ to $2700 \mathrm{~kg} / \mathrm{m}^{3}$. This showed that the result of this study is reliable. For porosity value results from this study is ranging from $0.47 \%-0.56 \%$. This finding was compared with a study conducted by [7], where the porosity value of shale ranging from $0.50 \%$ to $0.90 \%$. Hence it showed that the result achieved by this study is reliable.

Based on the Table 4 the point load streng index, $\mathrm{Is}_{(50)}$ value for all samples are from $1.87 \mathrm{MPa} \sim 2.28 \mathrm{MPa}$ in average. According to [3], the $\mathrm{Is}_{(50)}$ value of shale ranging 0.06 $\mathrm{MPa} \sim 2.56 \mathrm{MPa}$. The Is $\mathrm{I}_{(50)}$ obtained in this study is reliable that showed a good agreement with previous study.

P-wave velocity value has been recorded for both field and laboratory test. Field test consists of two layers which the results ranging between $2000-4000 \mathrm{~ms}^{-1}$. Meanwhile, for laboratory test consist of ten samples and the results achieve ranging between $2545 \mathrm{~ms}^{-1}$ $3067 \mathrm{~ms}^{-1}$. The average P-wave velocity value for field test is $2900 \mathrm{~ms}^{-1}$ meanwhile for laboratory test were $2845 \mathrm{~ms}^{-1}$. The differences between two values were $55.3 \mathrm{~ms}-1$. Nevertheless, the value is still reliable to be interpreted as shale. According to [5] the Pwave velocity value for shale ranging from $2000 \mathrm{~ms}^{-1}$ to $4100 \mathrm{~ms}^{-1}$. The $\mathrm{P}$-wave velocity value from both field and laboratory test were compared (Fig. 4). This comparision was made to identify that the P-wave velocity values obtainded in the laboratory represented the rock mass. The result shows that the range of P-wave measured in the labortaory accomodated to the field value. 


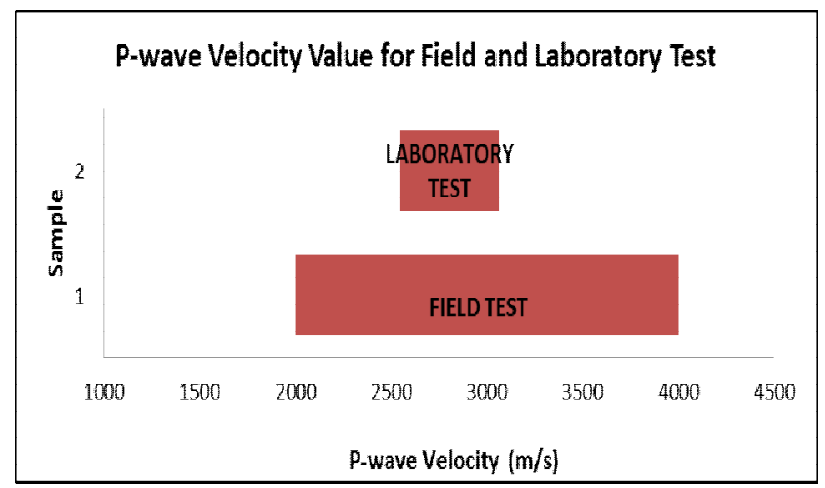

Fig. 4. P-wave velocity value for field and laboratory test

The relationship between P- wave velocity value and point load strength index value Is (50) shows a good correlation on both parameters (Fig. 5). This can be acknowledged that the point load strength index value can be predicted by knowing the P-wave valueof the rock either from seismic field test or by PUNDIT test.

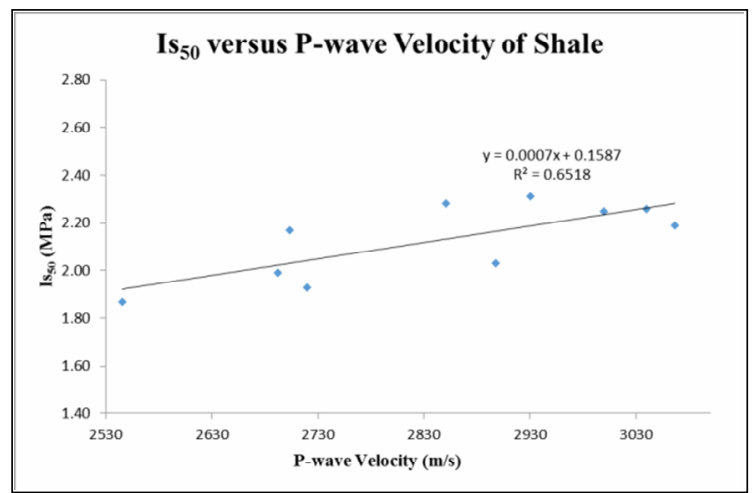

Fig. 5. Correlation between P-wave velocity value and point load strength index value

Referring to the Table 2, it shows that after estimating UCS values using a correlation as per Equation (2), the UCS value obtained ranging between $30.87 \mathrm{MPa} \sim 36.65 \mathrm{MPa}$. According to [3] the value for UCS for shale in Kenny Hill Formation is ranging between $5.33 \mathrm{MPa} \sim 35.23 \mathrm{MPa}$. Hence the value obtained in this study is considered reliable as compared to previous study. As the UCS value is an important parameter in engineering to measures the rock strength, therefore, the correlation between P-wave velocity and UCS value can be acknowledged without the need of conducting UCS test. This means that by knowing the P-wave velocity value based on seismic refraction test, we can estimate the UCS value . Resulting from the correlation as in Fig. 6 an empirical relationship between UCS and P-wave velocity value is developed. The empirical relationship equation produces is stated in Equation (6). 


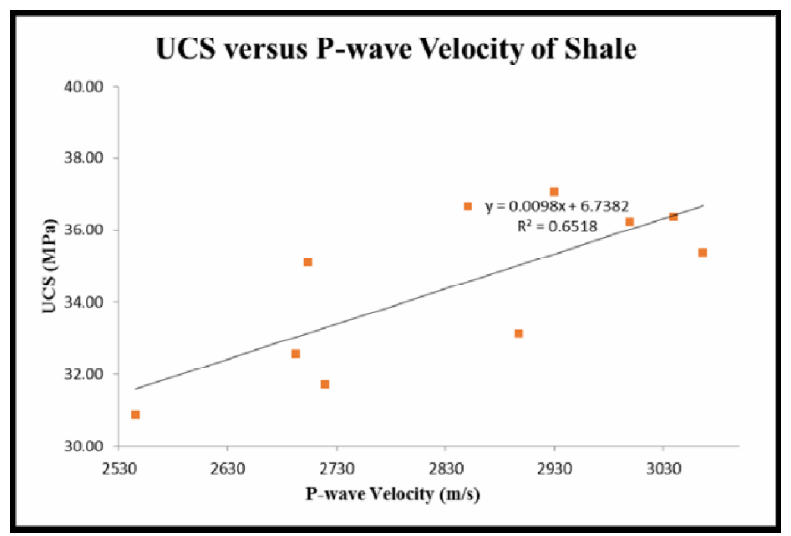

Fig. 6. Correlation between P-wave velocity value and UCS

$$
U C S=0.0098 \mathrm{Vp}+6.7382
$$

In general from this study that was guided by [8], P-wave velocity value was achieved via seismic refraction method as a field test, then the data were analyzed using OPTIM software. Ultrasonic pulse velocity (PUNDIT) test on the other hand also produce P-wave velocity value, but it was conducted in the laboratory. Meanwhile Point Load Test (PLT) was conducted to identify the rock's mechanical properties. Both PUNDIT and point load strength index value was achieved using samples collected at the same location where the seismic field test conducted. A correlation has been developed between P-wave velocity test and point load strength index value and furthermore predictions of uniaxial compressive strength test was produced.

Based on the empirical relationship, it shows that to find the UCS value of shale this empirical equation can be used. This equation is achieved based on the regression value produced from the graph. By acknowledging this empirical relationship, it is now easier to identify UCS value in without the needs of physical testing on samples as well as borehole and sample collecting procedures. Due to seismic test that produces P-wave velocity value which performed on the ground surface, we can acknowledge the compressive strength index value that is important for design factor. Both UCS and E value are one of the most important parameters in rock engineering properties. Many equations can be produced via these parameters for example settlement, (S) equation as per stated in Equation (4) by [1]. By knowing $E$ value, settlement $(\mathrm{S})$ of foundation on rock value can be calculated. Refering to the Table 2 it shows that the Young's Modulus $(E)$ value ranging between $16.01 \mathrm{GPa} \sim 18.34 \mathrm{GPa}$ matched to [4].

\section{Conclusions}

This study is pointing out the reliability of using geophysical method prior to site investigation. The other aim is to predict uniaxial compressive strength by using P-wave velocity and point load strength index. The results revealed that a correlation between Pwave velocity value and point load test strength index value can be acknowledged via an empirical relationship equation. Settlement equation could be determined from P-wave velocity as well as Young's modulus value. In a nutshell, this study is beneficial to engineering development and more of such studies are needed in future due to the contribution in sustainable type of living, 


\section{References}

[1] T.Y. Irfan, G.E., Powell, Foundation design of Caissons on granitic and volcanic rocks, Geo Report No.8., Geotechnical Engineering Office, Civil Engineering Department, Hong Kong. (1995)

[2] T. Bozdag, Indirect rippability assessment of coal measure rocks, Doctoral Dissertation, METU, Ankara, (1988)

[3] Z. Mohamed, K. Mohamed, H. Awang, Empirical strength models, elastic modulus and stiffness of weathered sandstone and shale as a composite rock, Electronic Journal of Geotechnical Engineering, 0730, (2007)

[4] C. Sachpazis, Correlating Schmidt hardness with compressive strength and Young's Modulus of carbonated rocks, Bull, Eng. Geol. Environ., 42,75-83 (1990)

[5] H. Kohen, The temperature dependence of seismic waves in ice, Journal of Glaciology, 13(67), 144-147 (1974)

[6] J.H. Schön, Physical properties of rock, Handbook of Petroleum Exploration and Production, Elsevier, USA, (2015)

[7] H.S. Poelchau, D.R. Baker, T. Hantschel, B. Horsfield, B.,Wygrala, Basin simulation and design of the conceptual basin model, Petroleum and Basin Evaluation, SpringerVerlag, New York, 3-70 (1997)

[8] International Society of Rock Mechanics Rock Characterization, Testing and Monitoring: Suggested Methods For Determining the Point Load Strength, Pergamon Press, Oxford (2007) 